\title{
Effective Factors in Marital Satisfaction in Perspective of Iranian Women and Men: A systematic review
}

Farzaneh Zaheri ${ }^{1}$, Mahrokh Dolatian ${ }_{2}^{2}$ Mohammad Shariati ${ }^{3}$, Masoomeh Simbar ${ }^{4}$, Abbas Ebadi ${ }^{5}$, Seyede Batool Hasanpoor Azghadi ${ }^{6}$

${ }^{1}$ Ph.D. Student of Reproductive Health, Department of Midwifery and Reproductive Health, School of Nursing and Midwifery, Shahid Beheshti University of Medical Sciences, Tehran, Iran

${ }^{2}$ Assistant Professor, Department of Midwifery and Reproductive Health, School of Nursing and Midwifery, Shahid Beheshti University of Medical Sciences, Tehran, Iran

${ }^{3}$ Associate Professor, Department of Community Medicine, School of Medicine, Tehran University of Medical Sciences, Tehran, Iran

${ }^{4}$ Professor, Department of Midwifery and Reproductive Health, School of Nursing and Midwifery, Shahid Beheshti University of Medical Sciences, Tehran, Iran

${ }^{5}$ Associate Professor, Behavioral Sciences Research Center, Nursing Faculty, Baqiyatallah University of Medical Sciences, Tehran, Iran

${ }^{6}$ Assistant Professor, Department of Midwifery and Reproductive Health, School of Nursing and Midwifery, Iran University of Medical Sciences, Tehran, Iran

Type of article: Systematic review

\begin{abstract}
Introduction: One of the most important factors and determinants of mental health, emotional stability of couples and successful marriage is marital satisfaction, a state that in most cases, males and females are satisfied with each other and their marriage. This review was conducted to survey the effective factors on marital satisfaction in view of Iranian men and women.

Methods: This systematic review surveys published articles from 2005 to 2015. First, scientific databases such as Pubmed/Medline, Scopus, Elsevier, Cochran library, Springer, Scientific Information Database (SID), IranMedex, Magiran and Medlib were searched using relevant key words and phrases. All published peerreviewed articles studied exploring associations between marital satisfaction and effective factors were considered for inclusion.

Results: According to results, the spiritual and religious, sexual and interpersonal factors, communication and interaction factors and mental health had positive impact on marital satisfaction in the vast majority of studies. Also in most articles, impact of some socio-demographic factors such as occupation, length of marriage, age, Number of children, economic factor and income had been emphasized.

Conclusion: In mate selection, it is necessary to note various criteria, including religious matters, moral, mental health, communication skills and sexual factor and action through education, counseling and treatment if there is problem.
\end{abstract}

Keywords: Marriage, Successful Marriage, Marriage Satisfaction, Systematic review

\section{Introduction}

One of the most important goals of marriage is the will to attain marital satisfaction (1). Marital satisfaction is a complex and multi-dimensional phenomenon, which has been extensively explored by the most diverse scientific fields (2). According to Schoen et al., marital satisfaction is a global evaluation of the state of one's marriage and a reflection of marital happiness and functioning. From an evolutionary perspective, marital satisfaction can be

\section{Corresponding author:}

Assistant Professor Dr. Mahrokh Dolatian. Department of Midwifery and Reproductive Health, School of Nursing and Midwifery, Shahid Beheshti University of Medical Sciences, Tehran, Iran.

Tel: +98.2188202517, Fax: +98.2188202517, Email: mhdolatian@gmail.com

Received: August 15, 2016, Accepted: November 21, 2016, Published: December 2016

iThenticate screening: November 14, 2016, English editing: November 26, 2016, Quality control: December 06, 2016 (C) 2016 The Authors. This is an open access article under the terms of the Creative Commons Attribution-NonCommercialNoDerivs License, which permits use and distribution in any medium, provided the original work is properly cited, the use is non-commercial and no modifications or adaptations are made. 
viewed as a psychological state of regulated mechanisms that monitor the benefits and costs of marriage to a particular person (3). In definition of marital satisfaction, experts agree that it subjectively assesses quality of relationship (4). It seems that factors which influence or contribute to marital satisfaction may differ across cultures. For example, a husband's income is a more important variable for marital satisfaction in Japan as compared to United States (3). After marriage, individuals seek a life full of happiness and satisfaction; therefore, more significant than the marriage itself is success in marriage and marital satisfaction $(5,6)$. As a result, a decrease in marital satisfaction not only creates an inappropriate atmosphere in a family but also leads to family instability and divorce (7). Therefore, due to the significance of the balanced function of the family and preventing it from breaking up, it is necessary to know the effective factors in marital satisfaction which is the strengthening basis for married life (8). In this regard, the present study was aimed at investigating the effective factors in marital satisfaction from the perspective of Iranian women and men.

\section{Material and Methods}

The present systematic review study was carried out in order to investigate the effective factors in marital satisfaction in perspective of Iranian women and men, in articles published during 2005-2015. First, the researcher used keywords like marital satisfaction, factors involved with marital satisfaction, and marital relationship, to search relevant research studies, study summary, and reviews in both English and Persian in reputable scientific databases including Cochran library, Springer, Scopus, Elsevier, Pubmed/Medline, IranMedex, Magiran. Finally, all Population-based cross-sectional, Cross-sectional studies in specific groups of society representative (randomized and non-randomized) studies that had focused on marital satisfaction among Iranian women and men over the last ten years were scrutinized. In so doing, studies that had focused on factors related to marital satisfaction were chosen. As a result, eighty three relevant articles were used.

\section{Results}

\subsection{Demographic factors}

One of the factors that is related to, and can affect marital satisfaction is the demographic factor which focuses on the couple's education, marriage age, age difference, marriage duration, working women and men (3), the existence and number of children, the spouse's economic situation (9), and cross-cultural marriage (10).

3.1.1. Marriage age can be an important and underlying factor in creating marriage consequences (11) which is determined according to specific environmental, economic, and cultural circumstances in any society (3). Most studies have referred to the age ranges of 18-25 and 24-30 years as suitable marriage ages for men and women, respectively (12-14) because some believe that marriage at these ages is accompanied with a higher quality of life and that marriage at the age of below 18 for women and 20 for men will likely be associated with divorce or failure (11) and decreased stability of marriage (15). In some studies, it was indicated that young and old married individuals were not satisfied with their married lives; however, dissatisfaction was higher among young married couples (16-17). It seems that the suitable marriage age is influenced by culture and geographical region (18).

3.1.2. Age difference with spouse or age appropriateness is an important but unnecessary factor in having a successful life and marital satisfaction. In some studies, between age differences and marital satisfaction there were negative statistically significant differences $(17,19)$ and in others positive statistically significant differences were observed (20). It is usually recommended that a woman should be 2-4 years younger than a man (13). According to specialists, an age difference of 6-8 years was considered to be appropriate to have a successful life (14).

In general, spouses' age difference cannot be generalized from one culture to another. This issue can be defined within cultural and geographical structures (18) and vary according to specific social criteria and traditions of each country. Different definitions have been proposed for the number of these years, which indicates cultural differences (17).

3.1.3. Marriage duration: Duration and particular phases are defined for every marriage. Existence of different phases for marriage, motivated researchers to evaluate marital satisfaction in each phase. It seems that due to the lack of complete agreement over important issues like raising children, financial problems, and relationship with relatives in the middle of married life, compared to the first-fifth year, dissatisfaction will be the result and grounds for incompatibility and instability will be established; however, when children become separated and independent of family, marital satisfaction is more than when they live with their family (21).

3.1.4. Appropriateness of educational level and homogeneity between university majors can be a positive and influential factor in couple's mutual understanding, because it provides sufficient motivation and appropriate cultural atmosphere for verbal and spiritual communication between couples, which creates grounds for deeper cultural and intellectual convergence $(13,22)$. Many studies in Iran have shown positive significant statistical relationship between educational level and marital satisfaction $(10,23-28)$. However, it does not mean lack of this 
will result in incompatibility and lack of understanding between couples, because such factors are interpreted based on the intellectual and epistemic background of the woman and the man $(13,22)$. The educational level of the spouse was an important factor among young adults in selecting their appropriate partners (29), and there was a significant difference between girls and boys in terms of this important factor (18).

3.1.5. Employment and adequate income earned by the man is correlated to better quality of life, and those men who did not have a permanent job or were unemployed over the last year were more prone to life separation (30) and a lower marital satisfaction (16). Moreover, a woman's job along with a man's occupation and income can help improve the quality of life and some dimensions of marital satisfaction (31). In this regard, a 2014 study by Mirzaee and colleagues showed that marital satisfaction scores in employed spouses of married men are significantly greater than the housewife spouses of married men in Kermanshah (32), but in a 2006 study carried out by Sadegh Moghadam and Co-workers, this relationship showed no statistically significant differences (33). A 2014 study by Zanjani and Baghiat showed that there was a significant relationship between marital satisfaction and employment status of female teachers in Karaj (formal employment or tuition employment), as life satisfaction in formal employment was higher than tuition employment (9).

3.1.6. Gender plays an important role in many aspects of life and the relationship between a woman and man. Women and men have different views about marital satisfaction. In a women's view, communication, understanding, family relationships, agreement, and income by both spouses are effective factors in marital satisfaction, while in a man's opinion, spouse's education, income by both spouses, understanding, agreement, family relationships, and communication are effective factors in creating satisfaction (34). But the majority of studies have emphasized on non-statistically significant relationship between marital satisfaction and gender (4, 17, 35-37).

3.1.7. Type of marriage in the present study refers to family or non-family marriage (37) and traditional or modern marriage (38). Although it may seem more successful due to better familiarity and cooperation in solving financial problems, family marriage has a negative side that can include family interferences, extension of family conflicts into the marriage, and so on, which can lead to a decrease in marital satisfaction and neutralize the positive effects (37). A 2014 study by Farahmand and Ahmadnia showed that marital satisfaction in modern spouse selection is higher than traditional methods and that this difference has been statistically significant in the men's group (4).

3.1.8. Existence and number of children: In the past, a family was typified as children and mother as caregiver. Nowadays, with an increase in educational level, attitudes toward having children have changed. Having children, especially boys, is no more an important concern for families. Many families are satisfied with having two children regardless of their gender. Increased educational level and governmental advertisement have caused families to be more concerned with providing quality care to children than their gender (9). A 2014 study by Zanjani and Baghiat showed that there were significant statistical differences between existence of children and marital satisfaction (9). In some of the studies, relationship between number of children and marital satisfaction has been inversely statistically significant $(10,20,28,37)$, While in the 2014 study by Mirghaforvand and colleagues and Zanjani and Baghiat, these differences were not statistically significant $(9,38)$.

3.1.9. Economic factor: Marriage is more of an economic relation and a secure social network than an emotional relationship. Income, job, properties, debt, and division of chores at home form the quality and stability of married life. In other words, income, expenditure, saving, and sharing money are inseparable components of married life in the current era. Financial issues are the commonest sources of conflicts in interpersonal, marital, and family relationships and appropriate employment and income are important issues in establishing, maintaining, and increasing marital satisfaction (39). It is observed that financial problems and low income can cause conflict, lower marital satisfaction $(33,40)$ and divorce between couples $(41)$. In some studies there was a positive correlation between marital satisfaction and economic situation $(9,33,37)$.

\subsection{Interpersonal factors}

Personality includes a set of characteristics and components that help with understanding and evaluating problems and provide the individual with abilities to create acceptable and effective cultural and social adaptability, or on the opposite they endanger the family and its psychological health $(42,43)$. Global evaluations have indicated that personality characteristics are different among individuals who are satisfied with married life and those who are not (44). The conducted studies focused more on investigating the relationship between the five personal factors of openness, extraversion, conscientiousness, agreeableness, and neuroticism and marital satisfaction. The results of most studies indicated that there is a reverse significant relationship between neuroticism and marital satisfaction $(20,45-49)$. 


\subsection{Psychological factors}

That women and men are sure about the psychological health of each other is one of the most important factors that help the success and stability of marriage (50), because disorder in psychological health reduces the chance of satisfactory relationships (51). After marriage, there is a positive interaction between marital satisfaction and psychological health (44). It was observed that the psychological profile of couples faced with incompatibility and dissatisfaction is unfavorable, and prevalence of mood and anxiety disorders was higher than those of the control group (52). Furthermore, there was a reverse relationship between marital satisfaction and couples' depression (51, $53)$ and anxiety (51).

\subsection{Interaction factor}

Emotions are created through a term called interaction. All individuals in their lives belong to groups, and one of the first groups that they belong to is the family whose members' relationship is intimate, stable, and personal. This entity can have the highest mental and emotional effects on its members. Interaction in the family means verbal communication, marital commitment, and mutual trust which create a suitable atmosphere to express the members' feelings (54).

3.4.1. Communication is one of the most important factors for survival, stability, and growth of family. Unfamiliarity with communication skills and inability to solve harmful family interactions and issues are among important factors in etiology of marital dissatisfaction (5). In a study carried out on 400 married women referring to medical-health centers in Borujen, it was indicated that the most marital problem was the inability to establish effective communication and direct issues in a correct way (23). A 2008 study by Abrahami and colleagues showed that there was a positive and significant correlation between marital satisfaction and communication (55).

3.4.2. Intimacy is attempted to move toward a complete communication at all levels or ability to reveal most cases about oneself. Intimacy can be considered as a process in which individuals try to get close to one another and discover similarities and differences in their emotions, thoughts, and behavior (49). A number of studies showed a significant positive correlation between marital satisfaction and intimacy (56-58).

3.4.3. Marital commitment is the individual's tendency to maintain marriage and stay loyal to spouse, family, and values for ever (23). It enables couples to be effectively flexible toward one another's desires. In the study carried out by Asoudeh (2010), traditional couples, along with other factors, focused on commitment, and nontraditional couples focused on trust (59). A 2010 study conducted by Mashak indicated a positive significant relationship between commitment and marital satisfaction (56).

\subsection{Spiritual and religious factors}

Religious beliefs play a significant role in strengthening and stability of marriage (60). A review including 94 metaanalysis studies referred to an average to strong relationship between religion and commitment and marital satisfaction. The results of the studies carried out on Muslim, Christian, and Jewish Americans indicated that religion affected the marriage stability through channels like anti-divorce beliefs and sharing religious beliefs among public (61). In different studies of appropriate criteria in spouse selection, adherence to religious beliefs and principles was among the first priorities $(12,60,62)$. After marriage, the results of studies indicated that there was a positive significant relationship between religious adherence and marital satisfaction $(12,60)$. In the study carried out by Khodayari Fard et al., it was concluded that religiosity had the highest relationship with the agreement between the couples and religious tendencies and emotions had the highest relationship with total marital satisfaction (63). Religious beliefs generally have a positive relationship with satisfaction with life (64) and help with improving, strengthening, and consolidating the relationship between couples and stability of marriage (65) and an increase in ethical commitment reduces the probability of paying attention to divorce (17).

\subsection{Sexual factors}

Sexual need has long been one of the most controversial human needs, and has occupied the human mind and affected human behavior in all periods throughout history, even when there was no culture and civilization as we know it today (64). In the family and marriage system, desirable sexual relationship (66) and sexual health are necessary and acceptable (59) and two of the most powerful predictors of marriage stability and success (15). According to the results of the study conducted by Khazaei, there was a significant relationship between sexual dysfunction and low marital satisfaction. Moreover, there was a relationship between sexual satisfaction and marriage duration, and individuals with marriage duration of under 15 years had higher sexual satisfaction (68). According to results of a study, there was a positive significant relationship between the score of sexual schema 
pattern (three subscales of passionate-romantic, explicit-comfortable, shy-cautious) and level of marital satisfaction (69). However, lack of marital satisfaction is 5 times higher among individuals without sexual satisfaction (70).

\section{Discussion}

Human life is composed of different stages and cycles, the most difficult and complicated of which is marriage and starting life. Marital satisfaction can lead to fulfillment of many physical and psychological needs, and in case of failure, couples and especially children will be faced with severe psychological trauma (71). It seems that numerous factors play a role in marital satisfaction. The couples' personality, the level of mutual understanding, intellectual maturity, sufficient mental balance, economic factors, computability, sexual satisfaction, love, and passion are among the most important factors in creating a satisfactory life (72). In the present study, effective factors in marital satisfaction were categorized in demographic, interpersonal, psychological, interaction, spiritual-religious, and sexual factors. So there was a discussion on the definite effect of some items related to demographic factors (age difference with the spouse, marriage duration, education, the number of children, economic situation, and income) on marital satisfaction. Also, there was no statistical relationship between marriage age and gender roles of man and woman with marital satisfaction. In regard to marriage age variable, some studies referred to dissatisfaction among young and old married individuals, but with a higher level among young individuals $(16,17)$. Maybe Acquiring selfcontrol skills and lack of unrealistic views at older ages lead to adapting expectations to realities of life (17). Moreover, paying attention to factors like good income, higher education, employment, and private home has been effective in reducing the divorce rate. Therefore, before marriage, young adults need to pay close attention to factors such as employment and an appropriate income source to enhance the economic level of their family, and after marriage, they should manage life expenses according to their income (73). The results of the studies about the effect of the five important personality factors on marital satisfaction were contradictory. In most cases a reverse significant relationship between neuroticism and marital satisfaction and a positive significant relationship between agreeableness and marital satisfaction were observed $(74,75)$. In addition to breaking balance and stability and developing unfavorable relationships, neuroticism is associated with negative social consequences, too, such that a lot of individual and social problems are caused by this factor. Therefore, paying attention to presence of this factor among couples needs to be given top priority by psychological health authorities (76). According to the evidence provided by different studies, personality and marital satisfaction help with predicting frustration or a healthy and stable survival of marriages, because personality is related to psychological sub-structures (74). Also, due to the positive impact of mental health (75) on marital satisfaction, paying attention to this factor before marriage, in selection of appropriate spouse, is necessary. Paying heed to mental health, leads to understanding this problem before marriage and taking action to resolve it and also improving mental health indices (family stress and social acceptance) (54). After marriage, training about problem solving can be an appropriate strategy to enhance marital satisfaction, and reduce psychological symptoms such as anxiety, depression, and interpersonal sensitivity (5). Positive and significant effect of appropriate relationship (76), intimacy (37), and commitment (56) on marital satisfaction has been proved in different studies. Therefore, paying attention to presence of some communication skills such as listening, speaking, and problem-solving is necessary to create an effective relationship in married life, and enhancing these skills before marriage is recommended by participating in relevant counseling classes (77). Moreover, most of the studies highlighted the positive effect of spirituality on satisfaction with and stability of life $(22,60)$. These guidelines include regulations on sexual relationships, gender roles, self-sacrifice, and solving conflicts in marital relationship. It seems that the most important religious factor is having similar religious emotions and tendencies between couples (41). Therefore, the selected individual's adherence to religious beliefs and principles (62) and couples with similar religious beliefs (78) are significant. Also, studies showed positive effects of sexual satisfaction on marital satisfaction $(38,70)$. Today, neglecting sexual issues or its related issues is the cause of many failures in marital life, moral lapses, treason, conflicts, immorality, wrongdoings and even crimes (13). So, it is necessary that family counselors and experience individuals train about sexual skills and intimacy before and after marriage (78), because sexual issues, despite their simplicity, are very complicated, and the individual needs to be well aware of his/her sexual responses and functions in order to create correct interactions and communication (19). In this regard, mass media can be used to educate and enlighten couples (64). In general, in order to prove the effect of some factors on marital satisfaction, more studies need to be carried out. Moreover, no studies on the relationship between appearance, cultural-ethnic, and family characteristics on marital satisfaction was found although beauty and physical appearance and attractiveness are among important criteria in marriage and its continuation (13), and have always been among important factors to select spouse among both men and women $(53,75)$. Moreover, there has been emphasis on this point that cultural-ethnic and family factors need to be taken into account while selecting spouse, because factors such as spouses with similar ethnicity (79) and family situation can affect marital satisfaction (80). Therefore, further studies should focus on this issue. In general, it is possible that 
all aspects have been investigated in Iran; however, the researcher could not get access to them through searching keywords or in some cases, access to articles was not completely possible; therefore, the abstracts of the articles were used. In some cases, there was no way to have access to the articles, which was one of the limitations of the present study. However, scrutinizing the studies carried out on Iranian couples over the last decade was one of the strengths of the present study. Moreover, examining the articles and their results in the form of a review indicates the necessity of conducting further studies regarding the effective factors in marital satisfaction.

\section{Conclusions}

By examining relevant articles and literature, it can be concluded that some factors such as interpersonal (extraversion and agreeableness), spiritual, religious, and sexual factors and communication and interaction skills affect marital satisfaction. Attention to these factors in creating and increasing marital satisfaction and success of marriage is very important and showed that it is necessary to teach marriage candidates in selecting a suitable partner. After reviewing the studies, it seems that research on some of the factors influencing the increase in marital satisfaction such as communication or intimacy is limited and further generalizable studies are necessarily to be done in this context. Also, it is necessary to investigate the factors and skills influencing the increase in marital satisfaction after marriage.

\section{Acknowledgments:}

The present paper was the result of PhD thesis in midwifery. The researchers would like to sincerely thank the Research Deputy, honorable professors of midwifery and reproductive health department of nursing and midwifery faculty of Shahid Beheshti, for their unwavering efforts and help in writing, editing and conducting this study.

\section{Conflict of Interest:}

There is no conflict of interest to be declared.

\section{Authors' contributions:}

All authors contributed to this project and article equally. All authors read and approved the final manuscript.

\section{References:}

1) Heshmati H, Behnampour N, Arabameri S, Khajavi S, Kohan N. Marital Satisfaction in Refereed Women to Gorgan Health Centers. Iran J Psychiatry. 2016; 11(3): 198-200.

2) Rebello K, Silva Junior MD, Brito RCS. Fundamental Factors in Marital Satisfaction: An Assessment of Brazilian Couples. Psychology. 2014; 5(7): 777-84. doi: 10.4236/psych.2014.57088.

3) Zainah AZ, Nasir R, Ruzy Suliza Hashim, Noraini Md Yusof. Effects of Demographic Variables on Marital Satisfaction. Asian Social Science. 2012; 8(9): 46-9. doi: 10.5539/ass.v8n9p46.

4) Farahmand Z, Ahmadnia SH. A gender study on the relationship between the ways (traditional and modern) of mate selection and mrital satisfaction of families in shiraz city. Iran social sciences studies. 2014; 11(42): 91-105.

5) Pakravan E, Haghayegh S, Nshatdoust H, Molavi H. Efficacy of problem solving method on the marital satisfaction and psychological profile of the couples of Brojen city. Culture counseling. 2014; 4(16): 15-31.

6) Narimani M, Porzoor P, Atadokht A, Abbasi M. The role of spiritual well-being and religious adherence in predicting marital satisfaction among nurses. Journal of Clinical Nursing and Midwifery. 2015; 4(3): 1-10.

7) Mirfardi A, Edalati A, Redzuan M. Relationships Between Background Factors and Female Marital Satisfaction. Journal of Social Sciences. 2010; 6(3): 447-52. doi: 10.3844/jssp.2010.447.452.

8) Copen CE, Daniels K, Vespa J, Mosher WD. First marriages in the United States: data from the 2006-2010 National Survey of Family Growth. Natl Health Stat Report. 2012; $21: 1$.

9) Zanjani HA, Baghait esfahani $Z$. The effect of employment and family life, on female teachers' satisfaction (A Case Study of Teachers' in Karaj). Journal of Specialized Social Science. 2014: 10(39): 13-39.

10) Maghsoodi S, Moidfar S, Tavakol M. Sociological study between social capital and marital satisfaction among couples in Kerman. Iran social studies. 2011; 5(1): 124-52.

11) Strong B, De vault ch F, Cohen TF. The marriage and family experiences intimate relationships in a changing society. USA: Linda Schrieber-granster. 2011.

12) Haghighizadeh $\mathrm{M}$, Karami Kh, Soltani $\mathrm{T}$. The criteria of spouse choosing in viewpoint of Ahwaz Jundishapur University of Medical Sciences students. Health scineces. 2010; 2(2): 44-54.

13) Moosavi R. Mate Selection; comparative study between factors in Islam with accepted criteria by the youngs of Kerman. Islām va Pazhūheshhāye Tarbīyat. 2012; 4: 141-64. 
14) Rezaeanlangroodi R, Azizinazahad M, Hashemi M. The investigation of biological and psychological of marriage criteria from the view points of Iranian University students with that of their parents. Procediasocial and behavioral sciences. 2011; 28: 406-10. doi: 10.1016/j.sbspro.2011.11.077.

15) Wayas SO. Psychosocial factors as predictors of marital stability among married women in private universities in Ogun state. Thesis Master in Covenant University. 2008. Available from: http://hdl.handle.net/123456789/540.

16) Yazdanpanah F, Khalili M, Keshtkaran Z. Level of marital satisfaction in couples living in Iran. Indian journal of research. 2015; 4(4): 4-7.

17) Sayadpour Z. Successful marriage: study of marital satisfaction in student. Ravanshensi Tahavoli. 2005; 1(2): 1-14. doi: 10.18869/acadpub.jnms.1.3.62.

18) Shahhosseini Z, Hamzehgardeshi Z, Kardan Souraki M. The effects of premarital relationship enrichment programs on marriage strength: A narrative review article. Journal of Nursing and Midwifery Sciences. 2014; 1(3): 62-72.

19) Rahmani A, Allah Goli L. Role of couple, s age gap on marital and sexual satisfaction. Aflak. 2009; 9(17): 15-22.

20) Attari Y, Amanollahi fard A, Mehrabizadeh honarmand M. Relationship between personality traits and personal-family factors with marital satisfaction staff of government offices in Ahvaz. Journal of Education and Psychology. 2006; 3(1): 81-108.

21) Abbasi M, Dehghani M, Mazaheri MA, Ansarinejad F, Fadaie Z, Nikparvar f, et al. Trend Analysis of Changes in Marital Satisfaction and Related Dimensions across Family Life Cycle. Journal of Family Research. 2010: 6(21): 5-22.

22) Haghighizadeh M, Karami Kh, Soltani T. The criteria of spouse choosing in viewpoint of Ahwaz Jundishapur University of Medical Sciences students. Health scineces. 2010; 2(2): 44-54.

23) Banaiean S, Parvin N, Kazemian A. Marital satisfaction of women referring to health care centers in Brojen. Holist Nurs Midwifery. 2006; 16(1): 1-5.

24) Zarea B, Safyari Jafarabad H. Relationship between affecting factors on marital satisfaction among married men and women in Tehran. Women studies. 2015; 13(1): 111-40. doi: 10.22051/jwsps .2015.1940.

25) Mazloom khorasani M, Ghanad M. Affecting causes and motives of marriage of 45-25 years old in Birjand and its relationship with marital satisfaction in 2006. Social sciences journal of Literature and Humanities faculty of Mashhad University. 2006; 3910: 143-74.

26) Wagheiy Y, Miri MR, Ghasemipour M. A survey about effective factors on the marital satisfaction in employees of two Birjand Universities. Birjand Medical Sciences of University Journal. 2009; 16(4): 4350.

27) Ziaee T, Jannati Y, Mobasheri E, Taghavi T, Abdollahi H, Modanloo M, et al. The relationship between marital and sexual satisfaction among married women employees at Golestan University of Medical Sciences, Iran. Iran J Psychiatry Behav Sci. 2014; 8(2): 44-51. PMID: 25053956, PMCID: PMC4105603.

28) Mirfardi A, Edalati A, Redzuan M. Relationships Between Background Factors and Female Marital Satisfaction. Journal of Social Sciences. 2010; 6(3): 447-52. doi: 10.3844/jssp.2010.447.452.

29) Foroudastan M, Arizi HR, Noori A. Educational Level as A Criterion for Choosing Spouse and Comparing It in Male and Female Students. Social Welfare. 2009; 8(33): 217-26.

30) Phek-hek-lang heng- haverkamp L. What makes a successful marriage? Doctorate of philsophy degree, national university of singapore. 2006; 123.

31) Rajabi G, Sarvestani Y, Aslani Kh, Khojastemehr R. Predicators of Marital Satisfaction in Married Female Nurses. IJN. 2013; 26(82): 23-33.

32) Mirzaie KH, Karimi KH, Shayryari P. Employment on Marital Satisfaction of Men. J of health and care. 2014; 16(3): 61-9.

33) Moghadam S, Askari F, Marouzi P, Shams H, Tahmasebi S. Comparison of marital satisfaction in houswives and employed women and their hausbands in Gonabad. Ofogh-e-Danesh. 2006; 12(2): 45-50.

34) Ayub N, Iqbal SH. The Factors Predicting Marital Satisfaction: A Gender Difference in Pakistan. The International Journal of Interdisciplinary Social Sciences. 2012; 6(7): 63-73. doi: 10.18848/18331882/CGP/v06i07/52112.

35) Nazari AM, Fathi R, Asadi M. The relationship between job satisfaction and demographic characteristics and marital satisfaction in male and female teachers in secondary schools of Dehdasht. Woman and family studies. 2013; 5(18): 145-55.

36) Bahari S. Marital satisfaction in married students and effective factors. New ideas in education. 2007; 2(4): 27-40. 
37) Askarian Omran S, Shaikhaleslami F, Tabari R, Kazemnejad lili E, Pariad E. Role of career factors on marital satisfaction of nurses. Nursing and Midwifery Community. 2016; 25(78): 102-9.

38) Mirghafoorvand M, Mohammadalizadeh charandabi S, Asghari Jafarabadi M, Tavananejad N, Karkhaneh M. Socio- demographic Predictors of marital satisfaction reproductive age of women, Tabriz 2011-12. IJOGI. 2013; 16(72): 1-12. doi: 10.22038 /ijogi.2013.1945.

39) Copur Z, Eker I. The relationship between financial issues and marital relationship. International Journal of arts \& Science. 2014; 7: 638-79.

40) Mirzaie KH, Taghadosi Z, Pakdaman M. The factors affecting the stability of marriage in Tehran. GUGEF. 2015; 4(4): 1-8.

41) Rabani R, Beheshti S. Experimental Study of the relationship between religiosity and life satisfaction. Journal of Social Sciences. 2011; 8(1): 79-102.

42) Shams M, Kajbaf M, Iranpanah N. Comparison of personality and demographic characteristics in divorced women and married women in Isfahan. Researcher. 2014; 6(8): 22-30.

43) Najarpourian S, Fathizadeh M, Etemadi O, Ghasemi V, Abedi M, Bahrami F. Personality Types and Marital Satisfaction. Interdisciplinary journal of contemporary research in business. 2012; 4(5): 372-83.

44) Alipour A, Rahimi A, Zare H. The relationship between mental health and marital satisfaction in married students Payame Noor University Of Tehran. Oroomieh medical journal. 2013; 24(7): 557-65.

45) Golestani E, Manzeri Tavakoli A, Manzeri Tavakoli H. Relationship of personality traits with marital satisfaction in women. JLSB. 2012; 2(5): 189-216.

46) Shakerian A. The role of personality trait dimensions and gender on predicting marital adjustment. Behbood. 2012; 16(1): 16-22.

47) Razavieh A, Moin L, Bohlooli Asl F. Personality trait roles and marital satisfaction in married employees' job satisfaction in martyr Foundation and Veterans Affairs Shiraz. Woman and society. 2011; 1(4): 1-18.

48) Razeghi N, Nikiju M, Kraskian Mujembari A, Zohrabi Masihi A. Relationship between Big Five Personality Factors and Marital Satisfaction. Transition psychology: Iranian psychology. 2011; 7 (27): 26977.

49) Javanmard GH, Mohamaddi Gharagoozloo R. The study of relationship between marital satisfaction and personality characteristics in Iranian families. Procedia- social and behavioral sciences. 2013; 84(9): 396-9. doi: 10.1016/j.sbspro.2013.06.573.

50) Ghazivakili Z, Norouzinia R, Kabir K, Karimi M. Mental Health of People Who Are Going to Marry and Its Relation to Some of Their Demographic Factors. Alborz University of medical sciences. 2014; 3: 81 -8.

51) Shahi A, Ghaffari I, Ghasemi K. Relationship between mental health and marital satisfaction. Behbood Journal. 2011; 15(2): 119-26.

52) Mansourinia MA, Etemadi O, Fathizadeh M, Hassanpour MA. The Survey of Pre-Marriage Instruction Effects on Couple's Satisfaction Level in Isfahan. New findings in psychology. 2011; 6(19): 65-78.

53) Bakhshi H, Asadpour M, Khodadadizadeh A. Correlation between marital satisfaction and depression among couples in Rafsanjan. The Journal of Qazvin Univ of Med Sci. 2007; 11(2): 37-43.

54) Rahimi I, Haghighatian M, Mohammadi A. Role of violence feeling in family interactions (Case study from Shahrekord). Police knowledge Journal. 2013; 1(3): 101-21.

55) Ibrahimi A, Jhanbozorgi M. Relationship between comunication skills and marital satisfaction. Psychology and Religion. 2008; 1(2): 147-64.

56) Mashak R. Relationship between love styles with marital satisfaction in married students. woman and culture. 2010; 1(2): 83-97.

57) Ihteshamzadeh $P$, Makvandi B, Bagheri A. Relationship between forgiveness, perfectionism and intimacy with marital satisfaction in veterans and their spouses. New finding in Psychology. 2009; 4(12): 123-36.

58) Haidary A, Ighbal F. The relationship between emotion regulation difficulties, styles of attachment and intimacy with marital satisfaction in couples of Fooladshahr Ahvaz. New finding in Psychology. 2010; 5(15): 115-34.

59) Asoodeh MH, Khalil SH, Daneshpour M, Lavasani GH. Factors of successful marriage: Accounts from self described happy couples. Procedia Social and Behavioral sciences. 2010; 5: 2042-6. doi: 10.1016/j.sbspro.2010.07.410.

60) Moslehi J, Ahmadi M. The role of religious life in marital satisfaction. Ravanshenasi Va Din. 2013; 6(2): 75-90.

61) Alghafli Z, Hatch T, Marks L. Relgion and relationships in muslim families: a qualitative examnination of Devout married muslim couples. Religions. 2014; 5(3): 814-33. doi: 10.3390/rel 5030814. 
62) Abbaszadeh M, Behi M, Darbandi M, Yousefi M, Jamlzadeh F. Criteria of spouse selection in the boy or girl students in Zabol universsity of medical sciences in 2008. Rostamineh. 2011; 2(3): 80-8.

63) Khodayarifard M, Shahabi RA, Akbari Zardkhaneh S. Relationship between Religious Attitude and Marital Satisfaction. Journal of Family Research. 2007; 3(10): 611-20.

64) Mortazavi M, Bakhshayesh A, Fatehizadeh M, Emaminiya S. The relationship between sexual frigity and marital conflict in women residing in Yazd. The Journal of Urmia University of Medical Sciences. 2014; 24(11): 931-21.

65) Hosseini Dowlatabadi F, Saadat S, Jahangiri S. The Relationship between Religious Attitudes and Marital Satisfaction among married personnel of departments of education in Rasht City, Iran. International Journal of Advanced Studies in Humanities and Social Science. 2013; 1(6): 608-15.

66) Aliakbari Dehkordi M. Relationship between women sexual function and marital adjustment. Journal of Behavioral Sciences. 2010; 4(3): 199-206.

67) Sehat F, Sehat N, Shahsiah M, Mohebi S, Abaraie Y. The effect of sex education on sexual satisfaction increase of couples' in Isfahan. Life Sci J. 2013; 10(5s): 31-5.

68) Khazaei M, Rostami R, Zaryabi A. The relationship between sexual dysfunctions and marital satisfaction in Iranian married students. Procedia-social and behavioral. 2011; 30: 783-5. doi: 10.1016/j.sbspro. 2011.10.152.

69) Karimnejad Niaragh S, Borjali A, Alavian F, Azartash SHandi F. Relationship between satisfaction and sexual satisfaction ptoject with marital satisfaction in married female students. Aflak. 2010; 6(20-21): 3541.

70) Taghizadeh ME, Kalhori E. Relation between Self Esteem with Marital Satisfaction of Employed Women in Payam-e Noor University. GMP Review. 2015; 18(2): 592-6. doi: 10.5901/mjss.2015.v6n6s6p41.

71) Kamaly A, Dehghani S, Ghasemi H. Meta-analysis of effectiveness of psychological interventions counseling on enhancing marital satisfaction (Iran: 2002_2012). Counseling and Psychotherapy Culture. 2014; 5(19): 95-122.

72) Rahmani A, Merghati khoei E, Sadeghi N, Allahgholi L. Relationship between Sexual pleasure and Marital Satisfaction. IJN. 2011; 24(70): 82-90.

73) Saeedfard T, Hajrezaie B, Jahanbazi B. Correlation between marital satisfaction and mental health in nurses of Tehran hospitals. J Life Sci Biomed. 2015; 5(2): 34-8.

74) Janati jahromi M, Moin L, Yazdani L. Compare the relationship between personality traits and marital satisfaction among employed women in Kazeroon. Woman and society. 2010; 1(2): 143-62.

75) Karimi S, Kazemi M, Hasankhani H, Kazemi S. Comparison of the demographic charactristics of couples requested divorce and normal couples in Sirjan during 2011. Journal of nursing midwifery. 2010; 4(3-4): 42-9.

76) Kwasi Adu I, Tulasi V, Attakumah D. Exploring Factors That Influence Sustainable Marriage In St. Francis College Of Education and St. Francis Demonstration Basic School Community, Hohoe. Mathematical Theory and Modeling. 2014; 4(13): 83-95.

77) Pourmarzi D, Rimaz S, Merghati khoii E. Educational needs for mental health promotion in engaged youth. SJSPH. 2013; 10(3): 1-14.

78) Arefi M, Mohsenzadeh F. Predicting of marital satisfaction on the basis of communication and sexual intimacy. Family counseling and psychotherapy. 2011; 1: 43-52.

79) Sahabi J, Khani S, Khani A. Marriage Patterns and its Relationship with Martial Satisfaction; (A Study on Married Students at Islamic Azad University, Sanandaj Branch. Sociological Studies of Youth Journal. 2012; 4(12): 77-112.

80) Sandhya SJ. Socio-Economic Status and Physical Attractiveness in Mate Selection Choice. International Journal of Scientific and Research Publications. 2013; 3(10): 1-4. 